\title{
Effects of Rifampicin Resistant rpoB Mutations on Antitermination and Interaction with nus $A$ in Escherichia coli
}

\author{
Ding Jun Jin ${ }^{1}$, Michael Cashel ${ }^{2}$, David I. Friedman ${ }^{3}$, Yoshikazu Nakamura ${ }^{4}$ \\ William A. Walter ${ }^{1}$ and Carol A. Gross ${ }^{1}$
}

\author{
${ }^{1}$ Department of Bacteriology \\ University of Wisconsin \\ Madison, WI 53706, U.S.A. \\ ${ }^{2}$ Laboratory of Molecular Genetics \\ National Institute of Child Health and \\ Human Development, Bethesda \\ MD 20892, U.S.A. \\ ${ }^{3}$ Department of Microbiology and Immunology \\ The University of Michigan Medical School \\ Ann Arbor, MI 48109, U.S.A. \\ ${ }^{4}$ The Institute of Medical Science \\ The University of Tokyo, P.O. Takanawa \\ Tokyo 108, Japan
}

(Received 28 December 1987, and in revised form 19 June 1988)

\begin{abstract}
Rifampicin resistant ( Rif $^{\top}$ mutations map in the rpoB gene encoding the $\beta$ subunit of Escherichia coli RNA polymerase. We have used our collection of 17 sequenced Rif ${ }^{\mathrm{r}}$ mutations to investigate the involvement of $E$. coli RNA polymerase in the antitermination systems enhancing expression of delayed early $\lambda$ genes or stable RNA. We have found that Rif $^{r}$ mutations affect both $\lambda \mathrm{N}$-mediated antitermination and the cellular antitermination system involved in synthesis of stable RNA. Because NusA is involved in antitermination and termination, we also investigated the interaction of NusA and RNA polymerase by determining whether Rif ${ }^{\mathrm{r}}$ mutations alter NusA-dependent termination or antitermination in cells with defective nusA alleles. We have shown that Rif ${ }^{r}$ mutations can either enhance or suppress the phenotypes of defective nusA alleles. Most Rif ${ }^{r}$ mutations alter the temperature range over which the nusA 1 allele supports $\lambda \mathrm{N}$-mediated antitermination. In addition, a number of Rif $^{\mathrm{r}}$ alleles restore termination to the $n u s A 10(\mathrm{Cs})$ and the nusA11(Ts) mutants defective in this process. Our results indicate that the region of the $r p o B$ gene defined by the Rif $^{\mathrm{T}}$ mutations is involved in the antitermination process and affects the activity of the NusA protein directly or indirectly.
\end{abstract}

\section{Introduction}

Antitermination of transcription was first identified as an important genetic regulatory mechanism from studies on bacteriophage $\lambda$ (for a review, see Friedman \& Gottesman, 1983; Friedman et $a l ., 1984)$. Progression through the $\lambda$ life cycle is controlled by two successive antitermination events, each of which enhances the transcription of genes downstream from terminators. The first antitermination event, mediated by $\lambda \mathrm{N}$ protein, results in increased expression of the $\lambda$ DNA replication genes and the $Q$ gene while the second mediated by the $Q$ protein, allows expression of the genes coding for host lysis and structural components of the bacteriophage.

The involvement of Escherichia coli proteins in $\mathrm{N}$-mediated antitermination has been investigated both genetically and biochemically. The Nus mutants identify a group of genetic loci that encode gene products involved in $\mathbf{N}$-mediated antitermination (for a review, see Friedman \& Gottesman, 1983). Nus mutants do not allow wild-type $\lambda$ to grow but permit the growth of $\lambda \mathrm{N}$-independent 
derivatives such as $\lambda$ nin5. The nin5 deletion removes the strong terminators interposed between the $\lambda \mathbf{P}_{\mathbf{R}}$ promoter and the $Q$ structural gene thus eliminating or reducing the requirement for $\mathrm{N}$-mediated antitermination. To date, five nus loci have been identified. The nus $A$ locus encodes an acidic $54,000 M_{\mathrm{r}}$ protein that binds to core RNA polymerase with high efficiency (Friedman, 1971; Kung et al., 1975; Greenblatt \& Li, 1981a,b; Ishii et $a l$., 1984b). Functionally, NusA modulates elongation and pausing (Kingston \& Chamberlin, 1981; Greenblatt et al., 1981; Schmidt \& Chamberlin, 1984; Greenblatt, 1984; Lau et al., 1983; Farnham et al., 1982; Fisher \& Yanofsky, 1983; Landick \& Yanofsky, 1984) and participates in both termination and antitermination (Greenblatt et al., 1981; Ward \& Gottesman, 1981; Nakamura et al., 1986a,b; Schmidt \& Chamberlin, 1987; Chamberlin et al., 1987). The nus $B$ locus encodes a very basic $15,000 M_{\mathrm{r}}$ protein (Swindle et al., 1981; Georgopoulos et al., 1980; Strauch \& Friedman, 1981; Ishii et al., 1984a). The other three nus alleles are in previously identified genes: nusC mutation map in $r p o B$ (Friedman et al., 1984), encoding the $\beta$ subunit of RNA polymerase; nusD mutations map in rho (Simon et al., 1979) encoding the transcription termination factor Rho and the nusE mutation (Friedman et al., 1981) alters rpsJ, encoding ribosomal protein S10. Recently, a $23,000 M_{\mathrm{r}} E$. coli protein called NusG was identified biochemically (Horwitz et al., 1987). The NusA, NusB, S10 and NusG proteins, in concert with $\mathrm{N}$ protein, modify host RNA polymerase at nut sites (Friedman et al., 1973; Adhya et al., 1974; Franklin, 1974; Salstrom \& Szybalski, 1978; Rosenberg et al., 1978; de Crombrugghe et al., 1979; Das \& Wolska, 1984; Goda \& Greenblatt, 1985; Greenblatt et al., 1986; Barik et al., 1987; Horwitz et al., 1987) rendering transcription resistant to termination at some, but not all, downstream terminators. The nut sites are likely to be recognized in the transcript and contain a stem and loop structure called box $B$ required for $\mathrm{N}$-entry, as well as the octamer sequence CGCTCTTA called boxA (Salstrom \& Szybalski, 1978; Friedman \& Olson, 1983; Warren \& Das, 1984; Olson et al., 1984; Peltz et al., 1985).

The extensive involvement of host proteins in $\mathrm{N}$-mediated antitermination suggests that antitermination might also be involved in host gene expression. In fact, expression of stable RNA has been found to be dependent upon an antitermination system, presumably to prevent termination at Rho-dependent terminators and other terminators that exist in the nascent non-translated stable RNA transcripts (Aksoy et al., 1984; Li et al., 1984; Holben \& Morgan, 1984; also reviewed by Morgan, 1986). This antitermination system shares some components with $\mathrm{N}$-mediated antitermination. $E$. coli carrying nusB5 mutations are defective in both antitermination systems (Sharrock et al., 1985). In addition, both types of antitermination seem to involve the boxA sequence (Li et al., 1984). It is likely, although it has not been demonstrated conclusively, that NusA is involved in cellular antitermination (Sharrock et al., 1985).

Little is known about the intrinsic terminating capacity of RNA polymerase or the nature of the interaction of RNA polymerase with the antitermination apparatus or with NusA. One way to probe these interactions is to examine the effect of RNA polymerase mutations on these processes. Mutations leading to rifampicin resistance map in $r p o B$ and some are known to affect the $\lambda$ antitermination process and other events involving the NusA protein (Georgopoulos, 1971; Ghysen \& Pironio, 1972; Sternberg, 1973). The Rif ${ }^{\mathbf{r}}$ mutant, rif501, confers partial $\mathrm{N}$-independence and also affects the ability of RNA polymerase to terminate at NusA-dependent terminators (Lecocq \& Dambly, 1976; Greenblatt et al., 1981). Other rifampicinresistant ( (if $^{r}$ ) mutations are reported to enhance the antitermination defect of cells containing the nusA1 mutation (Sternberg, 1976; Baumann \& Friedman, 1976). However, there has been no systematic study of the effects of Rif ${ }^{\mathrm{r}}$ mutations on antitermination of $n u s A$ mutants.

We have identified 17 rifampicin-resistant ( $R$ if ${ }^{\mathrm{r}}$ ) mutations, affecting 14 different amino acids in the middle of the $\beta$ subunit, many of which alter the ability of RNA polymerase to terminate in vivo at Rho-dependent or Rho-independent terminators (Jin \& Gross, 1988; Jin et al., 1988). Based upon the number of identical isolates at each position, we have argued that this set of mutations is likely to include most of the Rif $^{r}$ mutations viable in haploid cells (Jin \& Gross, 1988). We report the effects of each of these Rif ${ }^{\mathbf{r}}$ mutations on $\lambda \mathbf{N}$-mediated and cellular antitermination. Because of the involvement of NusA in these antitermination processes as well as in termination, we also specifically ask about the interaction of RNA polymerase with NusA. We determine whether any of the Rif ${ }^{r}$ mutations alter NusA-dependent antitermination and termination in cells with defective nusA alleles. Our results indicate that the Rif $^{r}$ mutations affect antiter mination and they either enhance or suppress the phenotypes of defective nusA mutants. Some of the effects on antitermination may be due to effects on termination capabilities, whereas other effects on antitermination may be due to altered interactions with NusA. These results suggest that the region of the $\beta$ subunit defined by the Rif $^{T}$ mutations is involved in the antitermination process and affects the activity of NusA protein either directly or indirectly.

\section{Materials and Methods}

(a) Bacterial strains, bacteriophage and plasmids

A description of the Rif mutations used in this study and the strains employed for measuring their phenotypes are presented in Table 1 . In every case, the Rif ${ }^{r}$ alleles were introduced into the strains by cotransduction with a linked Tn10 marker as described (Jin \& Gross, 1988). The 
Table 1

Strains used in this study

\begin{tabular}{|c|c|c|}
\hline Strain & Relevant genotype & Source/reference \\
\hline MGl655 & E. coli K12 wild-type su ${ }^{\circ}$ & CGSC \\
\hline CAG3307 & nusAl derivative of MG1655 & This work \\
\hline N5261 & SA500his ilv galE490 $($ chll $)-b l u)^{\Delta 8}\left(\lambda \Delta \mathrm{BAM} N^{+} c 114 \Delta \mathrm{H}\right)$ & Ward et al. (1983) \\
\hline N5283 & Same as N5261 except $\lambda \Delta B A M$ carries Nam mutations & M. Gottesman \\
\hline CAG8333 & nusA1 derivative of $\mathrm{N5261}$ & M. Singer \\
\hline K37 & galK2 rpsL200 & CGSC \\
\hline K1914 & nusA $10(\mathrm{Cs})$ derivative of $\mathrm{K} 37$ & Schauer et al. (1987) \\
\hline CAG8102 & $r p s L^{+}$derivative of $\mathrm{K} 37$ & M. Singer \\
\hline CAG3844 & nus $A 10(\mathrm{Cs})$ derivative of CAG8102 & This work \\
\hline CAG3846 & nusA11(Ts) derivative of CAG8102 & This work \\
\hline YN2458 & R594 nusA11(Ts) & Nakamura et al. (1986a) \\
\hline $\begin{array}{l}\operatorname{Rif}^{\mathrm{t}}(r p o B) \\
\text { allele }\end{array}$ & Amino acid residue affected & Amino acid change \\
\hline 3445 & $\Delta(507-511)$ & $\begin{array}{l}\Delta \text { Gly, Ser, Ser, Gln, Leu } \\
\text { and inserts Val }\end{array}$ \\
\hline 101 & 513 & Gln to Leu \\
\hline 8 & 513 & Gln to Pro \\
\hline 113 & 516 & $\Lambda \mathrm{sp}$ to $\Lambda \mathrm{sn}$ \\
\hline 148 & 516 & Asp to Val \\
\hline 3051 & 517 & Insert Gln and Asp \\
\hline 3595 & 522 & Ser to Phe \\
\hline 2 & 526 & His to Tyr \\
\hline 3401 & 529 & Arg to Cys \\
\hline 3402 & 529 & Arg to Ser \\
\hline 114 & 531 & Ser to Phe \\
\hline 3449 & $\Delta 532$ & $\Delta$ Ala \\
\hline 3443 & 533 & Leu to Pro \\
\hline 3370 & 563 & Thr to Pro \\
\hline 111 & 564 & Pro to Leu \\
\hline 7 & 572 & Ilv to Phe \\
\hline 3406 & 687 & Arg to His \\
\hline
\end{tabular}

efficiency of $\lambda$ plating (e.o.p.t: see below) was determined in Rif ${ }^{r}$ derivatives of MGl655 and CAG3307. N-mediated antitermination was assayed in $\mathrm{Rif}^{\mathrm{r}}$ derivatives of $\mathrm{N5261}$ and CAG8333. Cellular antitermination was assayed in Rif $^{r}$ derivatives of CAG8102 carrying plasmid pES3 (described below). The effect of the Rif ${ }^{r}$ mutations on the termination efficiency of nusA 10(Cs) and nusA11(Ts) was determined in Rif ${ }^{\mathbf{r}}$ derivatives of K1914 and CAG3846 carrying pFS4 (described below), respectively.

Bacteriophage $\lambda^{+}, \lambda \mathrm{Nam} 53$ and $\lambda$ nins were from W. Dove.

Plasmid $\mathrm{KKG} 1800$ contains promoter $\mathrm{P}_{g a l}$ inserted upstream from the galK structural gene, while pKG1810 contains the terminator $\mathrm{T}_{152}$ interposed between $\mathrm{P}_{g a l}$ and galK. Both plasmids were obtained from K. McKenney and derived from plasmid pK01 (McKenney et al., 1981).

\section{(b) Construction of $p E S 3$ and $p E S 4$}

Plasmids pES3 (see Fig. 2) and pES4 (see Fig. 3) were constructed to allow measurement of $\operatorname{rrn} A$ transcription antitermination activity by comparative measurements of galK gene expression. Both plasmids contain the strong $r r n A$ Pl promoter transcribing the galK gene with 2 tandem transcriptional terminators ( $r m B \mathrm{Tl}$ and $\mathrm{T}_{\mathrm{IS} 2}$ ) interposed to dampen galK expression to the point where colony color on galactose MacConkey plates is sensitive to

$†$ Abbreviations used: e.o.p.. efficiency of plating; Cs, cold-sensitive; $T s$, temperature-sensitive; bp, basepair(s). the presence of a modified box $A$ region in pES3. Both plasmids were derived from a pKG1800 plasmid containing an IS2 terminator in the SmaI site $180 \mathrm{bp}$ upstream from the ATG of the galK gene (McKenney et al., 1981). The pES3 and pES4 plasmids were constructed by replacing the EcoRI-HindIII gal promoter fragment of pKG1800-IS2 with various portions of a pPSI plasmid (or its subclones) that contains a fusion between the rrnA promoter region and the $r r n B$ terminator region (Sarmientos et al., 1983). The rrnA Pl promoter is on an EcoRI-HindIII fragment containing sequences from -262 to +31 (relative to the RNA start site). The $\operatorname{rrnB}$ T1 terminator was inserted as a HindIII fragment (containing positions 2418 to 2607 of Brosius et al., 1981). In $\mathrm{pES} 3$, but not $\mathrm{pES4}$, a modified box $A$ region fragment spanning positions 1347 to 1426 of Brosius et al. (1981) was obtained from pPSl subclones that contained a $\mathrm{T}$ to $\mathrm{G}$ change at position 1379 and a deletion of 3 bases (ATC) at positions 1390 to 1392 . These spontaneous changes result in a boxA region sequence of ... TGCTCGTTAACAATTT - -AAGA ..., which permits less readthrough than the wild-type $b \circ x A$ sequence (M. Cashel, unpublished). Nonetheless, the presence of this modified boxA fragment in pES3 enables galK expression despite the presence of 2 otherwise highly efficient terminators in wild-type hosts (see Results).

\section{(c) General bacterial and bacteriophage techniques and media}

Cells were grown in M9-glucose complete medium (M9glucose supplemented with amino acids, nucleosides and 
vitamins) (Miller, 1972), NZY medium + maltose (Maniatis et al., 1982) or LB (Miller, 1972). LB, NZY and MacConkey-galactose plates were made as described by Miller (1972) or Maniatis et al. (1982). Tetracycline $(10 \mu \mathrm{g} / \mathrm{ml})$, ampicillin $(50 \mu \mathrm{g} / \mathrm{ml})$ and rifampicin $(50 \mu \mathrm{g} / \mathrm{ml})$ were added when indicated.

Competent cells were prepared by the $\mathrm{Ca}^{2+}$ shock method following growth in LB (Mandel \& Higa, 1970) and were stored at $-70^{\circ} \mathrm{C}$. Transformations were performed as described by Morrison (1979) and transformants were plated on selective plates after outgrowth for $2 \mathrm{~h}$.

Bacterial growth was followed by measuring a change in optical density at $450 \mathrm{~nm}$ (minimal medium) or $600 \mathrm{~nm}$ (broth).

P1 transductions were performed as described by Miller (1972).

\section{(d) Efficiency of $\lambda$ plating (e.o.p.)}

Cells $(0 \cdot 1 \mathrm{ml})$ of a fresh overnight culture grown on $\mathrm{NZY}+$ maltose were infected with about $5 \times 10^{3} \lambda$ phage. Following adsorption at $37^{\circ} \mathrm{C}$ for $15 \mathrm{~min}$, cells were plated with $3 \mathrm{ml}$ of NZY top soft agar on prewarmed fresh NZY plates. Plates were incubated overnight at the indicated temperature and $\lambda$ plaques were counted. When the e.o.p. was within a factor of 2 of that exhibited by wild-type cells, the strain was considered permissive for $\lambda$ growth. Strains unable to grow $\lambda$ exhibited an e.o.p. of $2 \times 10^{-4}$ or lower.

\section{(e) Enzyme assays}

Galactokinase (GalK) activity was measured from cells grown in M9-glucose complete medium using the assay described by McKenney et al. (1981) except that sodium deoxycholate $(0.3 \%, \mathrm{w} / \mathrm{v})$ was present in the lysis buffer. GalK activity is expressed as a differential rate of synthesis and is calculated from the slope of the line generated when enzyme activity is plotted versus cell growth. The slopes reported were based on samples taken at 3 to 4 times during log phase growth and are calculated as cts $/ \mathrm{min} \times 10^{3} \mathrm{Gal}_{-} \mathrm{PO}_{4} / A_{450}$ normalized to a reaction mixture containing $8 \mu \mathrm{Ci} / \mu \mathrm{mol}\left[{ }^{14} \mathrm{C}\right]$ galactose. A slope of $1000 \mathrm{cts} / \mathrm{min}$ Gal-PO $\mathrm{PO}_{4} / A_{450}$ is defined as $1 \mathrm{U}$. Every differential rate was determined at least twice. Duplicate determinations deviated less than $25 \%$ from the average value. When the galK gene was carried on a plasmid, the differential rate of synthesis was divided by the $\beta$-lactamase activity determined as described by Tomizawa (1985) to correct for copy number differences between strains. The $\beta$-lactamase activity was determined in duplicate on one of the lysates used for measuring the differential rate of galactokinase synthesis. We verified that the $\beta$-lactamase activity measurements were an accurate reflection of copy number by quantifying copy number by hybridization with ${ }^{32} \mathrm{P}$ labeled pES4 as described by Adams \& Hatfield (1984). The relative copy number measurements obtained by dot blots analysis agreed with that obtained from $\beta$-lactamase assay (D. J. Jin, unpublished results).

\section{(f) $S_{1}$ mapping}

We used the $S_{1}$ nuclease method of Berk \& Sharp (1978) to compare the fraction of transcripts that read through terminators in pES3 or pES4 following initiation at promoter $\operatorname{rrnA} \mathrm{P} 1$. Total E. coli RNA was prepared from mid-log cultures $\left(A_{450 \mathrm{~nm}}=0.5\right)$ growth at $37^{\circ} \mathrm{C}$ in

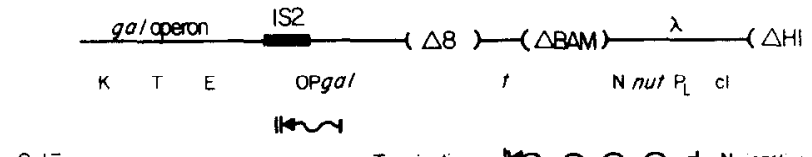

Gal

Termination ton $\sim \mathrm{N}$ inactive

$\mathrm{Gal}^{+} \mathrm{\sim} \sim \sim \sim m \sim n N$ active

Figure 1. $P_{L}$ gal fusion. The lambda $P_{L}$ promoter is contained on a cryptic prophage located close to the $E$. coli gal operon. Deletions $\triangle B A M$ and $\Delta H I$ remove all $\lambda$ genes with the exception of $N$, rex, and $c I$. The $c \mathrm{I}$ repressor gene is inactivated by the $c \mathbf{I} 14$ mutation, thereby allowing constitutive leftward transeription from $\mathrm{P}_{\mathrm{L}}$ towards the nearby $E$. coli gal operon. The only $\lambda$ gene expressed is N. Expression of gal from its cognate promoter is prevented by the galE490 mutation, an IS2 insertion in the leader region that causes termination of transcription. When the $\lambda \mathrm{N}$ function is active, transcription from $P_{L}$ is insensitive to the termination signals of $t$ and IS2 enabling expression of the gal operon. To maximize expression of gal, the gal operon was brought closer to the $\mathrm{P}_{\mathrm{L}}$ promoter by the large chromosomal deletion $c h l D$-blu ${ }^{\Delta 8}$ (adapted from Ward $e t$ al., 1983, with permission).

M9-glucose complete medium +ampicillin by the hot phenol extraction method of Salser et al. (1967). RNA/DNA hybridization conditions were those used by Berk \& Sharp (1978). All hybridizations were done with excess DNA. RNA samples (adjusted to $100 \mu \mathrm{g}$ of RNA per sample with tRNA) were hybridized to labeled DNA probe for overnight at $37^{\circ} \mathrm{C}$, digested with $S_{1}$ nuclease (170 units/reaction; Boehringer-Mannheim) for $1 \mathrm{~h}$ at $37^{\circ} \mathrm{C}$. The $\mathrm{S}_{1}$-resistant DNA fragments were resolved on a $12 \%$ or $5 \%(\mathrm{w} / \mathrm{v})$ polyacrylamide gel containing $50 \%$ (w/v) urea (Maxam \& Gilbert, 1980). The experiments were quantified by measuring the radioactivity in DNA fragments cut from gels. Data for each transcript were based on duplicate determinations at several RNA concentrations.

\section{Results}

\section{(a) Most Rifr mutations affect} $N$-mediated antitermination

We used two different types of assays to determine whether any of the Rif $^{r}$ mutations affected $\mathrm{N}$-mediated antitermination. First, we examined the efficiency of plating (e.o.p.) of $\lambda$ and several of its derivatives on the mutant strains (see Materials and Methods). We determined whether any of the Rif ${ }^{\mathbf{r}}$ mutations affected the e.o.p. of $\lambda^{+}$ but not $\lambda$ nins on lawns of either nus $A^{+}$or nusA1 bacteria. Because $\lambda^{+}$requires $N$-mediated antitermination for its lytic growth while $\lambda$ nin 5 does not, bacterial strains able to grow $\lambda$ nins but not $\lambda^{+}$are likely to be defective in $\mathrm{N}$-mediated antitcrmination. In addition, we determined whether any Rif ${ }^{r}$ mutations render $\lambda$ growth independent of $\mathrm{N}$ by asking if any of the Rif ${ }^{r}$ mutations can support the growth of the $\lambda \mathrm{Nam} 53$ phage, which cannot express functional $\mathbf{N}$ protein in hosts lacking a suppressor tRNA. 
Table 2

rpoB3595 bypasses the requirement for $N$ from $\lambda P_{R}$ but not from $\lambda P_{L}$

\begin{tabular}{|c|c|c|c|c|}
\hline \multirow{2}{*}{$\begin{array}{l}r p o B \\
\text { allele }\end{array}$} & \multicolumn{2}{|c|}{$\begin{array}{l}\text { גNam53 plaque formation } \\
\text { in MG1655 }\end{array}$} & \multicolumn{2}{|c|}{$\begin{array}{l}\text { Expression of galK from } \lambda P_{L} \\
\text { in } N 5283\left(N 5261 N^{-}\right)^{b}\end{array}$} \\
\hline & $32^{\circ} \mathrm{C}$ & $40^{\circ} \mathrm{C}$ & $32^{\circ} \mathrm{C}$ & $40^{\circ} \mathrm{C}$ \\
\hline$r p o B^{+}$ & - & - & $\leq 0.5^{\mathrm{c}}$ & $\leq 0.5$ \\
\hline 3595 & - & + & $\leq 0.5$ & $\leq 0.5$ \\
\hline Others ${ }^{\mathrm{d}}$ & - & - & $\leq 0.5$ & $\leq 0 \cdot 5$ \\
\hline
\end{tabular}

${ }^{a}+$, permissive for phage growth; - , e.o.p. $<2 \cdot 0 \times 10^{-4}$ relative to that in nonsense-suppressing bacteria.

${ }^{b}$ Values are expressed in GalK units as defined in Materials and Methods.

'A GalK value $\leq 0.5$ is not distinguishable from the background value.

See Table 1

To determine the magnitude of these effects, we used a second assay in which the rate of galK synthesis reflected the extent of $\mathrm{N}$-mediated antitermination. In strain N5261, expression of the gal operon is dependent on antiterminated transcripts originating from the $\lambda \mathrm{P}_{\mathbf{L}}$ promoter (Fig. $\mathbf{1}$ ). We transduced each of the Rif ${ }^{\top}$ alleles into N5261 and CAG8333 (N5261 nusA1) and then measured galK expression to quantify the effect of each Rif ${ }^{\mathrm{T}}$ mutation on $\mathrm{N}$-mediated antitermination.

(i) Bypass of the need for

$N$-mediated antitermination

One Rif ${ }^{r}$ mutation, rpoB3595, allowed 2 Nam53 to grow at $40^{\circ} \mathrm{C}$ but not $32^{\circ} \mathrm{C}$ indicating that it permitted $\lambda$ growth independent of $\mathbf{N}$ at high temperature (Table 2). The wild-type strain and other Rif ${ }^{\top}$ mutants did not permit $\lambda \mathrm{N} a m 53$ to form plaques (Table 2). Interestingly, although transcription from $\lambda P_{R}$ (as assayed by $\lambda$ growth) is $N$ independent, transcription from $\lambda \mathrm{P}_{\mathrm{L}}$ as assayed by galK expression from $\lambda \mathrm{P}_{\mathrm{L}}$ was not increased above the background in the rpoB3595 derivative of N5261 N- (Table 2). The fact that expression from $\mathrm{P}_{\mathrm{L}}$ is not increased rules out the possibility that the $\lambda$ N-independent growth arises from partial suppression of the Nam defect in rpoB3595 strains. The rif501 mutation has the same phenotype as rpo B3595 (Lecocq \& Dambly, 1976). As discussed below, the sequence change leading to Rif', is shared between the two strains (Jin \& Gross, 1988).

\section{(ii) Defects in $N$-mediated antitermination in nusA ${ }^{+}$strains}

$\lambda^{+}$forms plaques on a strain containing the rpoB111 allele only at high temperature (Table 3 ). The inability of a strain with the rpoB111 allele to allow $\lambda^{+}$plaque formation at $32^{\circ} \mathrm{C}$ results from a defect in $\mathrm{N}$-mediated antitermination since rpoB111 allows גnins plaque formation at $32^{\circ} \mathrm{C}$ (Table 3 ). K. Hammer and M. Gottesman, who originally isolated the rpoB111 allele (which they called sck-2), have also found that it restricts $\lambda$ growth at low temperature (Hammer et al., 1987). Consistent with the $\lambda$ plaque formation phenotype, expression of galK in N5261 rpoB111 was reduced tenfold at $32^{\circ} \mathrm{C}$ (Table 3). Measurement of GalK indicated that the rpoB111 strain is also defective in $\mathrm{N}$-mediated antitermination at $42^{\circ} \mathrm{C}$, although the defect is apparently not severe enough to inhibit $\lambda$ growth (Table 3). rpoB111 was the only Rif allele found to affect $\mathrm{N}$-mediated antitermination in a nus $A^{+}$strain (Table 3 ).

\section{(iii) Alterations in $N$-mediated antitermination in nusAl strains}

In nusA1 strains, $\mathbf{N}$-mediated antitermination is defective at high temperature (Friedman, 1971;

Table 3

rpoB111 inhibits $\lambda N$-mediated antitermination in a nusA ${ }^{+}$strain

\begin{tabular}{|c|c|c|c|c|c|c|}
\hline \multirow{2}{*}{$\begin{array}{l}r p o B \\
\text { allele }\end{array}$} & \multicolumn{4}{|c|}{$\begin{array}{r}\lambda \text { Plaque formation in MG } 1655^{\mathrm{a}} \\
\lambda^{+} \\
\lambda \operatorname{nin} 5\end{array}$} & \multicolumn{2}{|c|}{$\begin{array}{l}\text { Expression of } g a l K \text { from } \\
\lambda P_{L} \text { in } N_{5261^{b}}^{b}\end{array}$} \\
\hline & $32^{\circ} \mathrm{C}$ & $42^{\circ} \mathrm{C}$ & $32^{\circ} \mathrm{C}$ & $42^{\circ} \mathrm{C}$ & $32^{\circ} \mathrm{C}$ & $42^{\circ} \mathrm{C}$ \\
\hline$r p o B^{+}$ & + & + & + & + & $1 \cdot 0$ & $1 \cdot 0$ \\
\hline 111 & - & + & + & + & $0 \cdot 1$ & 0.2 \\
\hline Others $^{\mathrm{c}}$ & + & + & + & + & d & d \\
\hline
\end{tabular}

a + , permissive for phage growth; - , e.o.p. $<2.0 \times 10^{-4}$

b The GalK units (measured as described in Materials and Methods) in each of the mutant strains are expressed relative to the units in the $r p o B^{+}$strain. The GalK units for the rpo $B^{+}$strain at $32^{\circ} \mathrm{C}$ and $42^{\circ} \mathrm{C}$ are $30 \cdot 0$ and $90 \cdot 0$ units, respectively.

see Table 1.

${ }^{d}$ GalK values for each of the other Rifr mutants differed less than 2 -fold from that of the wild-type strain. 
Table 4

Some Rif mutations interfered with $\lambda N$-mediated antitermination in nusAl strains

\begin{tabular}{|c|c|c|c|c|}
\hline \multirow{2}{*}{$\begin{array}{l}r p o B \\
\text { allele }\end{array}$} & \multicolumn{2}{|c|}{$\begin{array}{c}\lambda \text { Plaque formation } \\
\text { in CAG3307 (MG1655 nusA } I)^{\mathrm{a}}\end{array}$} & \multicolumn{2}{|c|}{$\begin{array}{l}\text { Expression of galK from } \lambda \mathrm{P}_{\mathrm{L}} \\
\text { in CAG8333 (N5261 nus } A I)^{\mathrm{b}}\end{array}$} \\
\hline & $32^{\circ} \mathrm{C}$ & $36^{\circ} \mathrm{C}$ & $32^{\circ} \mathrm{C}$ & $36^{\circ} \mathrm{C}$ \\
\hline $\operatorname{rpo} B^{+}$ & + & + & 1.0 & $1 \cdot 0$ \\
\hline 3445 & - & - & $0 \cdot 1$ & $0 \cdot 1$ \\
\hline 8 & + & - & 0.3 & $0-3$ \\
\hline 113 & + & - & 0.3 & $0 \cdot 2$ \\
\hline 148 & + & - & 0.6 & $0 \cdot 3$ \\
\hline 111 & - & - & $<0.1$ & $<0 \cdot 1$ \\
\hline
\end{tabular}

${ }^{a}+$, permissive for phage growth; - , e.o.p. $<2.0 \times 10^{-4}$.

b The GalK units (measured as described in Materials and Methods) in each of the mutant strains are expressed relative to the units in the $r p o B^{+}$strain. The GalK units for the rpo $B^{+}$strain at $32^{\circ} \mathrm{C}$ and $36^{\circ} \mathrm{C}$ are 20.0 and $12 \cdot 0$ units, respectively

Friedman \& Baron, 1974). Strains carrying the nus $A 1$ allele allow $\lambda$ plaque formation normally at low temperature but are unable to allow $\lambda$ plaque formation above $37^{\circ} \mathrm{C}$ (Tables 4 and 5 ). We asked if any of the Rif $^{r}$ alleles altered $\mathrm{N}$-mediated antitermination in nusA1 strains. All but one Rif ${ }^{r}$ mutations altered the temperature range over which the $\mathbf{N}$ mediated antitermination system was functional in $n u s A 1$ strains (Tables 4 and 5), suggesting that the Rif region of the $\beta$ subunit plays an important role in modulating $\mathrm{N}$-mediated antitermination.

Five of the Rif ${ }^{\mathrm{r}}$ mutations inhibited antitermination in nusA1 strains. nusA1 strains containing these Rif ${ }^{r}$ mutations were unable to support $\lambda$ plaque formation at $36^{\circ} \mathrm{C}$ (Table 4). Of these $\mathrm{Rif}^{\mathrm{r}}$ mutants, two were unable to allow $\lambda$ plaque formation at $32^{\circ} \mathrm{C}$. These five Rif $^{5}$ nusAl mutants all allowed $\lambda$ nins plaque formation at $32^{\circ} \mathrm{C}$ (D. J. Jin, data not shown) suggesting that the defect in $\lambda$ plaque formation reflected inability to carry out $\mathrm{N}$-mediated antitermination. Measurement of GalK in $\mathrm{N5261}$ nusA1 confirmed that these five Rif ${ }^{\mathrm{r}}$ mutations decreased $\mathrm{N}$-mediated antitermination (Table 4). These strains have reduced expression of galk at both $32{ }^{\circ} \mathrm{C}$ and $36^{\circ} \mathrm{C}$. Strains containing rpoB111 and rpoB3445 that were most restrictive for $\lambda$ growth also showed the greatest reduction in galK expression. Comparison of the extent of $\mathrm{N}$ mediated antitermination with the ability to allow $\lambda$ plaque formation indicates that $\lambda$ plaque formation is prevented (e.o.p. $<2 \times 10^{-4}$ ) when the amount of antitermination is reduced about tenfold from that in wild-type cells at $32^{\circ} \mathrm{C}$.

A total of 11 of the Rif $^{\mathrm{r}}$ mutations partially suppressed the nusA1 phenotype and permitted $\lambda$

Table 5

Some Rif mutations suppress the defect of nusA1 mutant in $\lambda N$-mediated antitermination

\begin{tabular}{|c|c|c|c|c|c|}
\hline \multirow{2}{*}{$\begin{array}{l}r p o B \\
\text { allele }\end{array}$} & \multicolumn{2}{|c|}{$\begin{array}{c}\lambda \text { Plaque formation } \\
\text { in CAG3307 (MG1655 nusA } 1)^{\mathrm{a}}\end{array}$} & \multicolumn{3}{|c|}{$\begin{array}{l}\text { Expression of galK from } \lambda \mathrm{P}_{\mathrm{L}} \\
\text { in CAG8333 (N5261 nusA1) }\end{array}$} \\
\hline & $32^{\circ} \mathrm{C}$ & $38^{\circ} \mathrm{C}$ & $32^{\circ} \mathrm{C}$ & $38^{\circ} \mathrm{C}$ & $42^{\circ} \mathrm{C}^{\circ}$ \\
\hline$r p o B^{+}$ & $t$ & - & $1 \cdot 0$ & $1 \cdot 0$ & $1 \cdot 0$ \\
\hline 101 & + & + & $1 \cdot 2$ & $5 \cdot 1$ & 12.0 \\
\hline 3051 & + & + & 0.9 & $2 \cdot 7$ & $2 \cdot 0$ \\
\hline 3595 & + & + & 0.7 & $2 \cdot 3$ & $4 \cdot 0$ \\
\hline 501 & + & + & 0.6 & $5 \cdot 1$ & $30 \cdot 0$ \\
\hline 2 & + & + & $1 \cdot 6$ & $3 \cdot 3$ & $5 \cdot 4$ \\
\hline 3401 & + & + & $1 \cdot 8$ & 58 & c \\
\hline 3402 & + & + & 0.8 & $2 \cdot 2$ & $3 \cdot 4$ \\
\hline 3449 & + & + & 1.4 & $2 \cdot 2$ & $4 \cdot 0$ \\
\hline 3443 & + & + & $1 \cdot 2$ & $1 \cdot 8$ & $2 \cdot 4$ \\
\hline 3370 & + & + & $2 \cdot 4$ & $7 \cdot 3$ & 23.0 \\
\hline 7 & + & + & 0.8 & 1.7 & $2 \cdot 4$ \\
\hline 3406 & + & + & $2 \cdot 3$ & $5 \cdot 1$ & $8 \cdot 0$ \\
\hline
\end{tabular}

${ }^{a}+$, permissive for phage growth; - , e.o.p. $<2.0 \times 10^{-4}$

b The GalK units (measured as described in Materials and Methods) in each of the mutant strains are expressed relative to the units in the $r p o B^{+}$strain. The GalK units for the rpo $B^{+}$strain at $32^{\circ} \mathrm{C}, 38^{\circ} \mathrm{C}$ and $42^{\circ} \mathrm{C}$ are $20 \cdot 0,4.8$ and $\leq 0.5$ units, respectively. A GalK value $\leq 0.5$ is not distinguishable from the background value.

'The strain containing rpoB3401 was unable to grow at $42^{\circ} \mathrm{C}$. 
plaque formation at $38^{\circ} \mathrm{C}$ (Table 5). These same mutations also caused increased galK expression at $38^{\circ} \mathrm{C}$ in $\mathrm{N5261}$ nusA1 (Table 5). This effect was dependent upon a functional $\mathbf{N}$; in the absence of $\mathbf{N}$, galK expression was undetectable (D. J. Jin, data not shown). Since these Rif ${ }^{r}$ alleles have little $(<2$ fold) effect on galK expression in the N5261 nus $^{+}$ strain, they are unlikely to affect initiation from the $P_{L}$ promoter (D. J. Jin, data not shown). Therefore, we conclude that the increased galK expression of these 11 Rif $^{r}$ mutations results from increased antitermination. Among these 11 strains, some showed significant enhancement of galK expression even at $42^{\circ} \mathrm{C}$. Two alleles, rpoB101 and rpoB3.370, had the greatest effects and increased $\mathrm{N}$-mediated antitermination 10 to 20 -fold in nusA1 strains at this temperature (Table 5).

We present the nusA1 suppression data for rif501 in Table 5 because these data suggested to us that rif501 has more than one mutation. The rif501 mutation is identical with that in rpoB3595 within the $200 \mathrm{bp}$ region sequenced to ascertain the mutational change conferring Rif $^{\mathrm{r}}$ (Jin \& Gross, 1988). The phenotypes of these strains were also identical (D. J. Jin, unpublished data) except when we examined the nusA suppression phenotype. The expression of galK is about sevenfold higher at $42^{\circ} \mathrm{C}$ in CAG8333 rif501 than in the CAG8333 rpoB3595 isogenic strain (Table 5). The mutation rpoB3595 arose spontaneously (J. Gardner, personal communication) while rif501 was obtained after nitrosoguanidine mutagenesis (Lecocq \& Dambly, 1976). The enhanced suppression of the nusA1 defect by rif501 could be explained if this strain carries additional mutations outside of the Rif region of $r p o B$.

\section{(b) The effects of Rifr mutations on the cellular antitermination system}

We used the pES3 vector described in Materials and Methods to determine whether any of the Rif mutations affected the cellular antitermination system involved in transcription of stable RNA. In pES3, sequences derived from the $\operatorname{rrn} A$ operon, including a box $A$ site, allow transcription through the strong $r r n$ T1 and IS2 terminators resulting in expression of galK. When the pES3 plasmid is carried in a galK $^{-}$strain, alterations in the amount of antitermination were detected as altered expression of galK

Rif $^{\mathbf{r}}$ derivatives of CAG8102, a galK ${ }^{-}$strain, were transformed with pES3 and screened on MacConkey-galactose-ampicillin plates (MGA plates) to determine whether they decreased galK expression from pES3. Most of the Rif' mutants gave the expected $\mathrm{Gal}^{+}$phenotype and had GalK activity similar to that in the $r p o B^{+}$strain (data not shown). However, three Rif ${ }^{\mathrm{r}}$ mutants, rpoB114, rpoB3449 and rpoB3443 were $\mathrm{Gal}^{-}$when transformed with pES3. The rate of galK expression in these strains was about tenfold lower than in the isogenic $r p o B^{+}$parental strain (Table 6).
Table 6

Some Rif ${ }^{r}$ mutants are defective in cellular antitermination

\begin{tabular}{lll}
\hline & \multicolumn{2}{c}{ GalK phenotype of pES3 in CAG8102 } \\
\cline { 2 - 2 } $\begin{array}{l}\text { rpoB } \\
\text { allele }\end{array}$ & $\begin{array}{c}\text { Colony color on } \\
\text { MGA plates }\end{array}$ & galK expression \\
\hline$r p o B^{+}$ & Red & $1 \cdot 0(75 \cdot 0)$ \\
114 & White/pink & $0 \cdot 1$ \\
3449 & White/pink & $0 \cdot 1$ \\
$\mathbf{3 4 4 3}$ & White/pink & $0 \cdot 1$ \\
Others & Red & $c$ \\
\hline
\end{tabular}

The GalK units (measured as described in Materials and Methods) in each of the mutant strains are expressed relative to the units in the rpo $B^{+}$strain. The value in parentheses indicates the value of GalK units in the $r p o B^{+}$strain.

bee Table 1.

GalK values for each of the other mutants differed less than 2 -fold from that of the rpo $B^{+}$strain.

Interestingly, these were the only three Rif ${ }^{r}$ alleles that do not affect any of the Rho-dependent or Rho-independent terminators we have assayed ( $\mathrm{Jin}$ et al., 1988).

The decreased expression of galK in strains containing these three Rif $^{r}$ mutants could result either from decreased initiation at $r r n A \mathrm{Pl}$ or from increased termination at one or both of the terminators located upstream of galK in pES3. To distinguish these possibilities, we " $S_{1}$ mapped" in vivo RNA originating from $\operatorname{rrn} A P 1$, using a probe that was $5^{\prime}$-end-labeled at the HindIII site (see schematic in Fig. 2). We found that the initiated transcript represents a similar fraction of total RNA in the $r p o B^{+}$and the three Rif ${ }^{r}$ mutant strains indicating that initiation at promoter $P l$ is not affected by the Rif ${ }^{r}$ mutations (Fig. 2(a)). A further $S_{1}$ mapping experiment using a probe $5^{\prime}$-end-labeled at the $S n a \mathrm{Bl}$ site downstream from the terminators (see schematic in Fig. 2) indicated that these three Rif ${ }^{r}$ mutants decreased readthrough of the pES3 terminators at least tenfold (Fig. 2(b)). These results indicate that the dramatic decrease in galK expression results from the fact that these three Rif ${ }^{r}$ mutations decrease the effectiveness of the cellular antitermination system involved in the synthesis of stable RNA.

\section{(c) The nusAl0(Cs) mutation affects termination in pES4}

Plasmid pES4 differs from pES3 in that it lacks the box $A$ sequence necessary for antitermination. Expression of galK in cells carrying pES4 is very low because transcription stops at the $r r n \mathrm{Tl}$ and $\mathrm{T}_{\text {IS2 }}$ terminators upstream from the galK structural gene. None of the Rif ${ }^{r}$ mutations increased expression of galK from pES4 (data not shown).

However, the nusA10(Cs) mutation, which prevents cell growth at $30^{\circ} \mathrm{C}$ and decreases the efficiency of the $\mathrm{N}$-mediated antitermination system (Schauer et al., 1987), does affect galK expression 

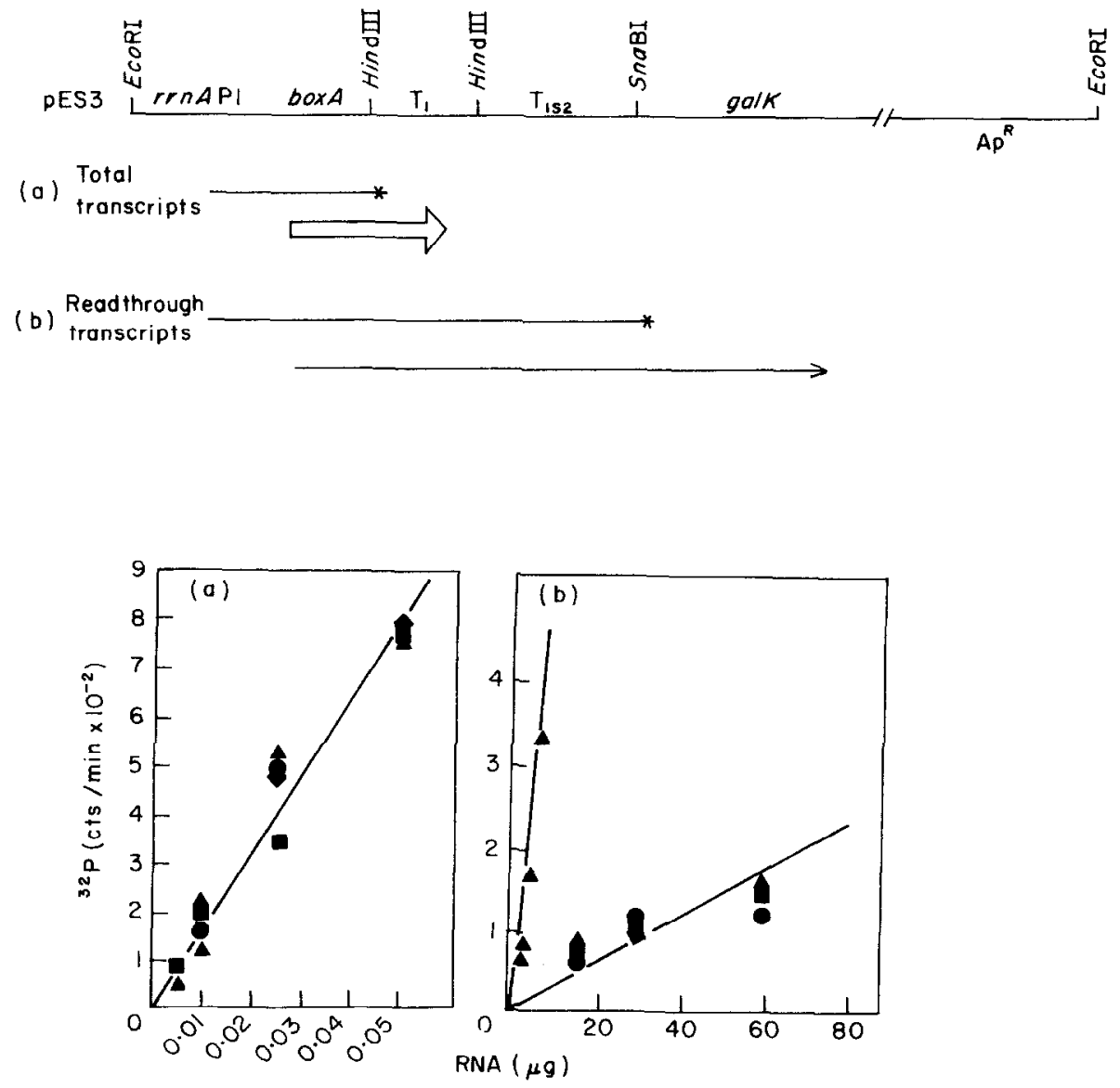

Figure 2. $\mathrm{S}_{1}$ nuclease mapping of the transcripts from $r r n A$ P1 in pES3 to analyze cellular antitermination in wildtype and 3 Rif $^{r}$ mutant strains. The schematic (not drawn to scale) outlines the strategy for mapping the transcripts initiating from $\operatorname{rrnA} \mathrm{Pl}$ and the transcripts that readthrough both the $\mathrm{T} 1$ and $\mathrm{T}_{\text {IS2 }}$ terminators. The mRNA transcripts are indicated with an arrowhead. The $5^{\prime}$-end-labeled $\left[{ }^{32} \mathrm{P}\right] \mathrm{DNA}$ fragment $\left({ }^{32} \mathrm{P}\right.$ indicated by $\left.{ }^{*}\right)$ used for hybridization is shown above the respective mRNA transcript. (a). Total transcripts initiating from $\operatorname{rrnA}$ P1. A 410 bp HindIII-EcoRI fragment $5^{\prime}$ end-labeled at the HindIII site was hybridized with increasing amounts of RNA extracted from $r p o B^{+}(\mathbf{A})$,

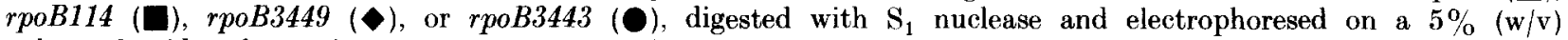
polyacrylamide gel containing $50 \%(\mathrm{w} / \mathrm{v})$ urea. The radioactivity in the protected fragment $(110 \mathrm{bp})$ was quantified by counting the excised fragment in $5 \mathrm{ml}$ of seintillation fluid (EcoLite). The amount of transcript hybridized is plotted versus increasing amount of total cellular RNA. (b). Transeripts extending beyond terminators $\operatorname{rrn} B \mathrm{Tl}$ and $\mathrm{T}_{\text {IS2. }}$. A $1100 \mathrm{bp} S n a \mathrm{BI}-E c o$ RI fragment 5 -end-labeled at the SnaBI site was used for hybridization with RNA from the

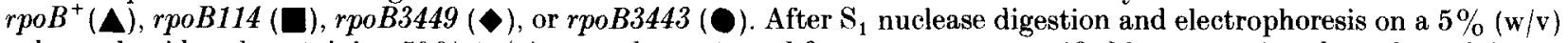
polyacrylamide gel containing $50 \%(\mathrm{w} / \mathrm{v})$ urea, the protected fragment was quantified by measuring the radioactivity in the fragment. The amount of transcript hybridized is plotted versus increasing amounts of total cellular RNA.

from plasmid pES4. When pES4 is carried in strains containing nusA $10(\mathrm{Cs})$, the cells are red on MGA plates and expression of galK is at least tenfold higher than in isogenic nus $A^{+}$strains at $37^{\circ} \mathrm{C}$ (Table 7). In fact, the level of galK expression from pES4 in nusA $10(\mathrm{Cs})$ cells is comparable to that of pES3 in $n u s A^{+}$cells (compare Tables 6 and 7 ).

The increased expression of galK from pES4 in the nus $A 10(\mathrm{Cs})$ strain resulted either from increased initiation at $r r n A P 1$ or from increased readthrough of one or both of the terminators located upstream from gal $K$ in $\mathrm{pES} 4$. To distinguish tiuse possibilities, we used $\mathrm{S}_{1}$ mapping of in vivo $\mathrm{RNA}$. We measured total RNA initiated from promoter P1 of $r r n A$ by $\mathrm{S}_{1}$ mapping with a probe that was $5^{\prime}$-end-labeled at the HindIII site and readthrough RNA using a probe that was $5^{\prime}$-end-labeled at the SnaBI site located downstream of both terminators (Fig. 3). We found that the iniliated transeript represents a similar fraction of total RNA in the nus $A 10(\mathrm{Cs})$ and $n u s A^{+}$strains indicating that initiation at promoter $\mathrm{Pl}$ is not significantly affected by the nus A 10 (Cs) mutation (Fig. 3(a)). In contrast, readthrough RNA is about 15 times more abundant in the $n u s A 10(\mathrm{Cs})$ strain than in the $n u s A^{+}$strain (Fig. 3(b)). This result indicated that the nusA 10 (Cs) allele is altered in terminator readthrough rather than initiation.

The pES4 plasmid might contain cryptic box $A$ sites. In this case, the increased terminator readthrough by the nusA10(Cs) allele could result from increased antitermination at cryptic boxA sites 
Table 7

Some Rif mutations suppress the termination defects of nusA mutants, as measured by galK expression from $p E S 4$

\begin{tabular}{|c|c|c|c|c|}
\hline \multirow[b]{2}{*}{$\begin{array}{l}\text { rpo } B \\
\text { allele }\end{array}$} & \multicolumn{2}{|c|}{$n u s A 10(\mathrm{Cs})^{\mathrm{a}}$} & \multicolumn{2}{|c|}{$n u s A 11(\mathrm{Ts})^{\mathrm{b}}$} \\
\hline & $\begin{array}{l}\text { Colony color on } \\
\text { MGA plates }\end{array}$ & $\begin{array}{c}\text { galK } \\
\text { expression }^{\mathrm{e}}\end{array}$ & $\begin{array}{l}\text { Colony color on } \\
\text { MGA plates }\end{array}$ & $\begin{array}{c}\text { galk } \\
\text { expression }^{c}\end{array}$ \\
\hline$r p o B^{+}$ & Red & $1 \cdot 0(70 \cdot 0)$ & Red & $1 \cdot 0(75 \cdot 0)$ \\
\hline 114 & White & $<0 \cdot 1$ & White & $<0.1$ \\
\hline 3449 & White & $<0.1$ & White & $<0 \cdot 1$ \\
\hline 3443 & White & $<0.1$ & White & $<0.1$ \\
\hline 3370 & Red & $0 \cdot 2$ & Red & $0 \cdot 2$ \\
\hline 111 & Red & 0.2 & Red & 1.0 \\
\hline 7 & Pink/red & $0 \cdot 2$ & Red & $0 \cdot 2$ \\
\hline 3406 & Pink/red & $0 \cdot 2$ & $\mathrm{~d}$ & d \\
\hline Others ${ }^{e}$ & Red & f & Red & $\mathrm{f}$ \\
\hline
\end{tabular}

In the rpoB $B^{+}$nus $A^{+}$strains containing pES4, GalK is 5.0 units (measured as described in Materials and Methods) and cells are white on MGA plates.

${ }^{a}$ Assayed at $37^{\circ} \mathrm{C}$.

b Assayed at $30^{\circ} \mathrm{C}$.

The GalK units (measured as deseribed in Materials and Methods) in each of the mutant strains are expressed relative to the units in the rpo $B^{+}$strain. The value in parentheses indicates the value of GalK units in the rpoB $B^{+}$strain.

d This double mutant grew too poorly to be assayed.

See Table 1 .

' GalK values for the other Rif' mutants differed less than 2 -fold from that of the $r p o B^{+}$strain.

rather than from decreased termination at one or both of the terminators. To distinguish between these possibilities we asked if the nusA10(Cs) allele can decrease termination of transcripts initiated from $\mathrm{P}_{\text {gal }}$ that do not contain a boxA sequence. Plasmid pKG1810 contains $\mathrm{T}_{\text {Is2 }}$ interposed between $\mathrm{P}_{\text {gal }}$ and galK. GalK expression is significantly higher in the nus $A 10(\mathrm{Cs})$ cells containing pKG1810 than in the isogenic wild-type cells (Fig. 4(a)). The effect of the nusA $10(\mathrm{Cs})$ allele on readthrough of $\mathrm{T}_{\text {IS2 }}$ from $\mathrm{P}_{g a l}$ is at least fivefold but could be much greater. We cannot calculate the magnitude of the effect since expression of galK in the us $^{+}$strain containing $\mathrm{pKGl} 1810$ is not significantly different from the background value for the assay (see legend to Fig. 4), and we cannot reliably measure terminator readthrough in the $n u s A^{+}$control. Increased galK expression in the $n u s A 10(\mathrm{Cs})$ strain does not result from increased initiation at $\mathrm{P}_{g a l}$. galK expression is virtually identical in $n u s A^{+}$and nus $A 10(\mathrm{Cs})$ strains containing the control plasmid pKG1800 lacking the terminator (Fig. 4(b)).

Taken together, these experiments establish that the nus $A 10(\mathrm{Cs})$ strain has a defect in termination at some terminators. Our conclusion that nus $A$ 1O(Cs) is defective in termination is consistent with recent work of Schmidt \& Chamberlin (1987) indicating that termination at $r r n \mathrm{~T} 1$, one of the two terminators present in pES4, is nus $A$-dependent in vitro.

\section{(d) Some Rifr mutations affect termination} in nusA mutant strains

We determined whether any of the Rif r mulations suppressed the termination defect of the $n u s A 10(\mathrm{Cs})$ strain at the terminators present in pES4. A total of seven of the Rif ${ }^{r}$ mutations suppressed this defect to some extent (Table 7). Among these, the three Rif ${ }^{r}$ mutations depressing cellular antitermination showed virtually complete suppression. These nusA10(Cs) Rif ${ }^{\mathrm{r}}$ mutants are white on MacConkey-galactose plates and have the same low level of galK expression from pES4 as does $n u s A^{+}$('lable 7). 'These data indicate that a number of the Rif ${ }^{r}$ alleles significantly restore the ability of this mutant NusA protein to carry out termination.

The nusA11(Ts) allele prevents cell growth at high temperature, is altered in $\mathrm{N}$-mediated antitermination and has been shown to be defective in termination at several terminators in vivo (Nakamura et al., 1986a,b). The level of galK expression in nusA11(Ts) cells containing pES4 is similar to that in nusA10(Cs) cells, indicating that $n u s A 11$ (Ts) is also defective in termination at pES4 terminators (Table 7). We tested the Rif ${ }^{\top}$ mutations to determine if any suppressed the nusA11(Ts) termination defect. Of the seven Rif alleles that decreased galK expression in the nus A10(Cs) strain, five also decreased galK expression in the nusA11(Ts) strain. There were no alleles that suppressed $n u s A 11(\mathrm{Ts})$ that did not also suppress nusA10(Cs)

Two of the Rif ${ }^{\mathrm{r}}$ alleles, rpoB3595 and rpoB2, are incompatible with $n u s A 10(\mathrm{Cs})$ and $n u s A 11(\mathrm{Ts})$ at $30^{\circ} \mathrm{C}, \quad 37^{\circ} \mathrm{C}$ and $40^{\circ} \mathrm{C}$ while bacteria carrying rpoB3401 and either nusA mutation grow extremely poorly (D. J. Jin, data not shown). These three Rif $^{\mathbf{r}}$ mutations are located near each other Each of these Rif $^{r}$ mutations permitted a great amount of readthrough at one or more of the Rho 


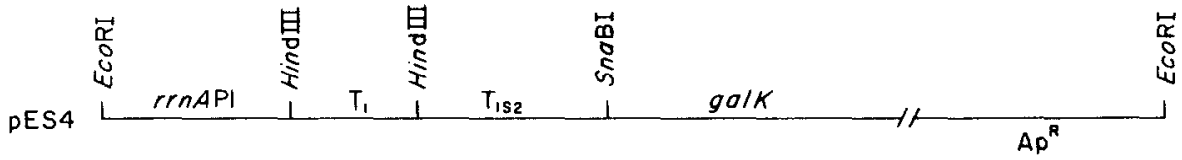

(a) Total

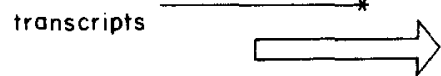

(b) Read through

transcripls
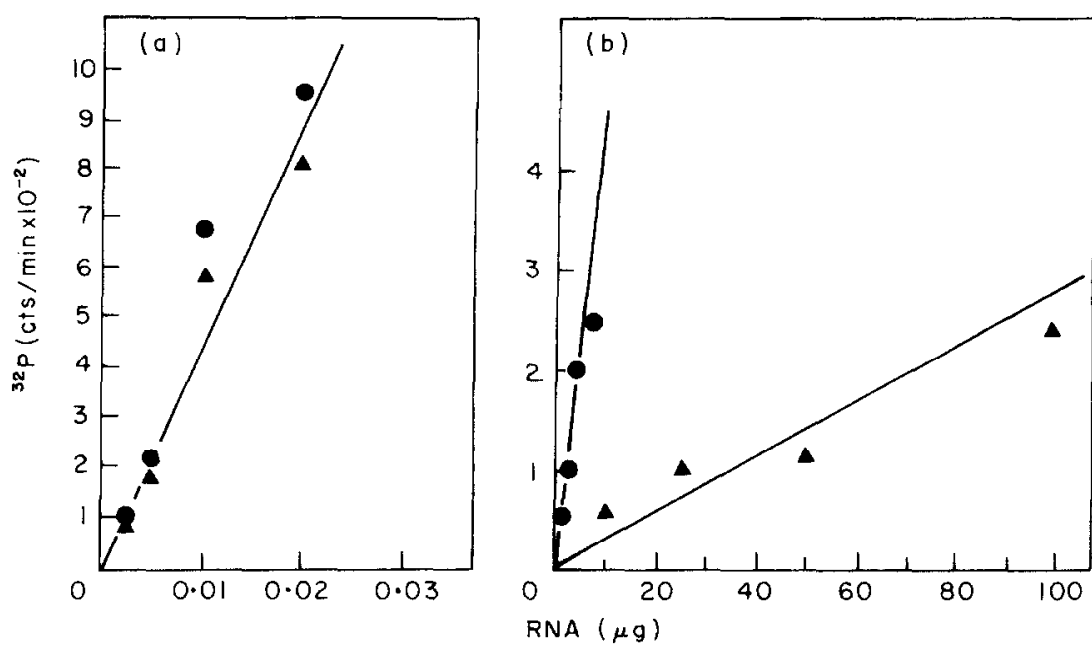

Figure 3. $\mathrm{S}_{1}$ nuclease mapping of the transcripts from pES4 to compare termination in nusA10(Cs) and nusA ${ }^{+}$ strains. The schematic (not drawn to seale) outlines the strategy for mapping the transcripts initiating from $r r n A$ P1 and the transcripts that readthrough both the $\mathrm{Tl}$ and $\mathrm{T}_{\mathrm{IS} 2}$ terminators. The $\mathrm{mRNA}$ transcripts are indicated with an arrowhead. The $5^{\prime}$-end-labeled $\left[{ }^{32} \mathrm{P}\right] \mathrm{DNA}$ fragment $\left({ }^{32} \mathrm{P}\right.$ indicated by $\left.{ }^{*}\right)$ used for hybridization is shown above the respective mRNA transcript. (a) Total transcripts initiating from $r r n A$ P1. A 330 bp HindIII-EcoRI fragment 5'-end-

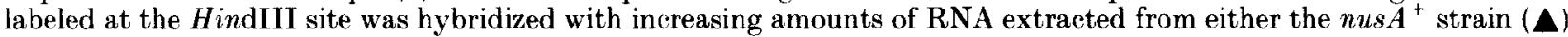
or the nusA10(Cs) strain (O), digested with $\mathrm{S}_{1}$ nuclease and electrophoresed on a $12 \%(\mathrm{w} / \mathrm{v})$ polyacrylamide gel containing $50 \%(\mathrm{w} / \mathrm{v})$ urea. The radioactivity in the protected fragment $(30 \mathrm{bp})$ was quantified by counting the excised fragments in $5 \mathrm{ml}$ of scintillation fluid (EcoLite). The amount of transcript hybridized is plotted versus increasing amounts of total cellular RNA. (b). Transeripts extending beyond terminators $\operatorname{rrn} B \mathrm{Tl}$ and $\mathrm{T}_{\mathrm{IS} 2}$. A $1020 \mathrm{bp}$ SnaBI $E c o$ RI fragment $5^{\prime}$-end-labeled at the $\$ n a B I$ site was used for hybridization with RNA from either the nus $A^{+}$strain (A) or $n u s A 10(\mathrm{Cs})$ strain (O). After $S_{1}$ nuclease digestion and electrophoresis on a $5 \%(w / v)$ polyacrylamide gel containing $50 \%(\mathrm{w} / \mathrm{v})$ urea, the protected fragment was quantified by measuring the radioactivity in the fragment. 'The amount of transcript hybridized is plotted versus increasing amounts of total cellular RNA.

dependent or Rho-independent terminators on which their effects were determined (Jin et al., 1988). Enhanced terminator readthrough may account for the incompatibility of these mutations with the nusA mutants defective in termination.

\section{Discussion}

We have investigated the effects of 17 Rif $^{r}$ mutations on processes involving the NusA protein. We determined whether any of the Rif mutations alter the ability of RNA polymerase to carry out $\lambda \mathrm{N}$-mediated or cellular antitermination. In addition, we have determined whether the presence of the Rif ${ }^{r}$ mutations affected the antitermination defect of nusA1 or the termination defect of nusA10(Cs) and nusA11(Ts). The phenotypes of the Rif $^{\mathrm{T}}$ mutations, summarized in Table 8 , indicate that they affect both termination and antitermination processes involving NusA protein.

In the discussion below, we first analyze the nature of the altered interaction exhibited by Rif $^{r}$ mutations with mutant nusA alleles. We then describe the antitermination phenotypes of the Rif mutations and consider the extent to which each of these phenotypes can be explained either by altered interaction with NusA or by the termination defects previously attributed to these alleles (Jin et al., 1988). In vitro studies will be required to determine if the mutant proteins do have the altered 


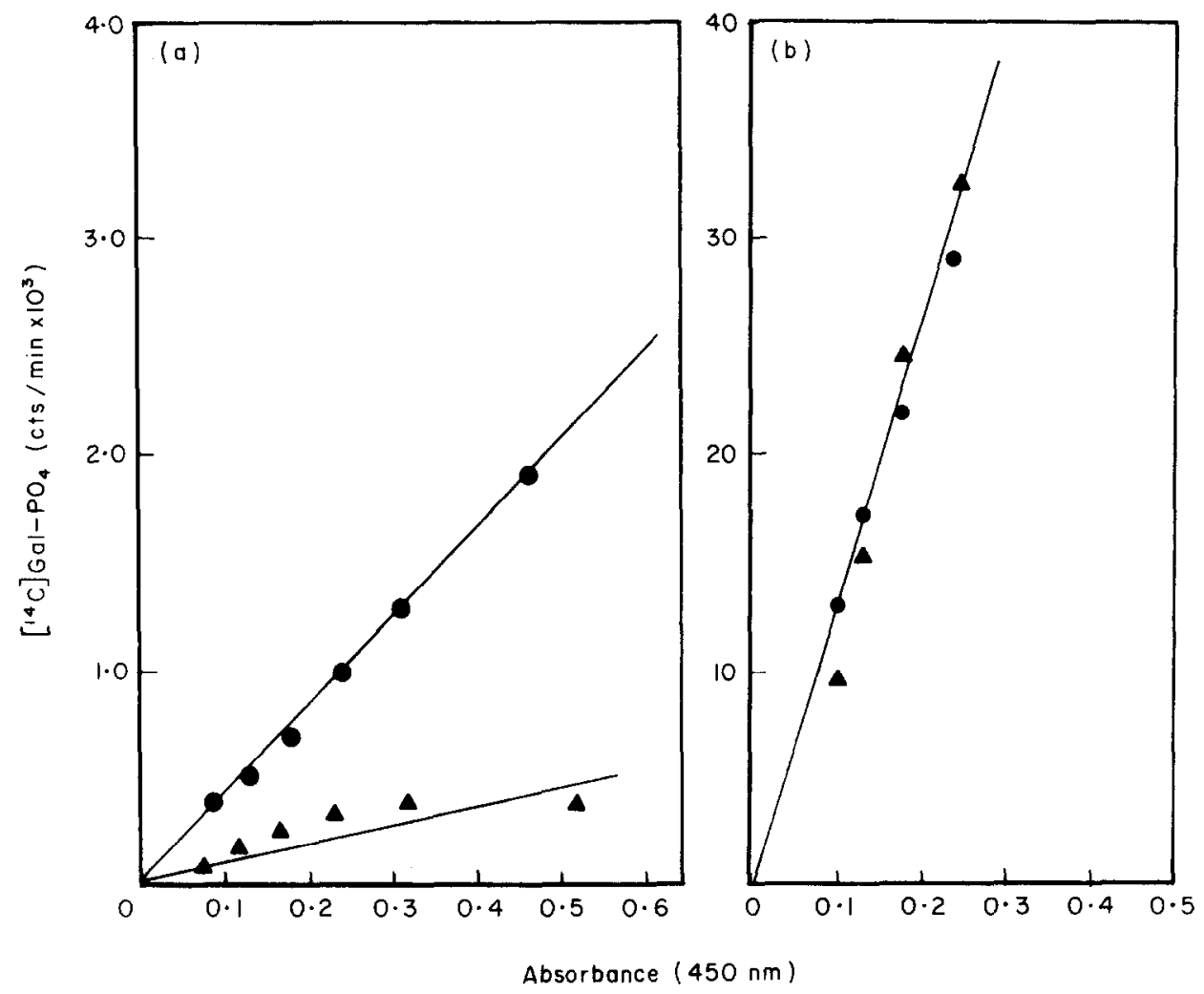

Figure 4. Comparison of galK expression in $n u s A^{+}$and $n u s A 10(\mathrm{Cs})$ strains containing either plasmid pKG1810 or pKG1800. GalK levels in strains containing pKG1810 reflect extent of termination at $\mathrm{T}_{\text {IS2 }}$ interposed between $P_{g a l}$ and galK in the pKG1810 while those in strains containing pKG1800 reflect initiation at $\mathrm{P}_{\text {gal }}$. Wild-type (CAG8102) and nusA10(Cs) (CAG3844) cells containing plasmid pKG1810 (a) or pKG1800 (b) were grown at $37^{\circ} \mathrm{C}$ in $\mathrm{M9-fructose}$ complete medium supplemented with ampicillin. The levels of galactokinase in $n u s A^{+}(\mathbf{\Lambda})$ and $n u s A 10(\mathrm{Cs})(\mathbf{O})$ cells are corrected for plasmid copy number and plotted versus $A_{450}$ (see Materials and Methods). A background of $\left[{ }^{14} \mathrm{C}\right] \mathrm{Gal}-\mathrm{PO}_{4}$ $(600 \mathrm{cts} / \mathrm{min})$ was subtracted from each experimental point.

interactions postulated here or whether some of the in vivo phenotypes result from other perturbations in cellular physiology.

\section{(a) Interaction of NusA and Rifr $R N A$ polymerase.}

We find that many of the Rif ${ }^{r}$ alleles located at the distal end of the Rif region (see Table 8) suppress the termination defects of the $n u s A 10(\mathrm{Cs})$ and the nusA11(Ts) alleles. This suggests that the Rif $^{r}$ RNA polymerases encoded by these mutant alleles interact differently with the mutant NusA proteins than does wild-type RNA polymerase. If NusA binds to RNA polymerase in the Rif region then the mutational changes in the Rif ${ }^{r}$ mutants could directly affect the interaction between NusA and RNA polymerase and the effects we observe could reflect altered protein contacts between the two proteins. Mutations that suppress a phenotype by altering protein contacts are generally found to be allele-specific (Jarvik \& Botstein, 1975). Our results indicate that of the seven alleles suppressing nusA $10(\mathrm{Cs})$, only the suppression by rpoB111 is allele-specific. Of the other six alleles suppressing nusA10(Cs), five also suppressed $n u s A 11(\mathrm{Ts})$ and the remaining allele (rpoB3406) grew too poorly to be assayed in combination with nusA11(Ts). This genetic criterion suggests that most of the effects we observe may not be due to altered protein-protein contacts. As an alternative explanation, the interaction could be indirect; for example, the mutant RNA polymerase might interact differently with some signal in the transcript to change the conformation of the ternary complex and affect the activity of NusA. Regardless of whether the effect of the mutant RNA polymerase on NusA activity is direct or indirect, because NusA is involved in both termination and antitermination processes, such alterations could have profound effects on the transcription process.

\section{(b) N-mediated antitermination phenotypes of Rifr mutations}

Three types of rpoB mutations affecting $\mathrm{N}$-mediated antitermination have been described: (1) N-bypass mutations, which allow $\lambda$ growth in the absence of $\mathrm{N}$-mediated antitermination (Lecocq \& Dambly, 1976); (2) NusC mutations, which restrict $\lambda$ growth in otherwise wild-type cells (Friedman et al., 1984); and (3) Snu mutations, which restrict $\lambda$ growth in nusAl cells at low temperature $\left(32^{\circ} \mathrm{C}\right.$ ) (Sternberg, 1976; Baumann \& Friedman, 1976). We have found all of these phenotypes among our Rif ${ }^{r}$ mutations and in 
Table 8

Summary of the effects of Rif mutations on antitermination and their interaction with nusA mutations

rpoB allele

Amino acid residue affected

Suppressed termination defect

in $n u s A 10(\mathrm{Cs})$

in $n u s A 11(\mathrm{Ts})$

$\mathrm{N}$ bypass for $\lambda$ plaque formation

Inhibition of $\lambda$ plaque formation in $n u s A^{+}$

Interfered with antitermination (A.T.) in nusA I

Suppressed nusA1 A.T. defect

Suppressed termination defect in rho15

Defect in cellular antitermination (with pES3 system)

$r p o B^{+} \quad 3445 \quad 101 \quad 8 \quad 113 \quad 148 \quad 30513595 \quad 2 \quad 34013402114344934433370111 \quad 7 \quad 3406$ $\begin{array}{lllllllllllllllll}507- & 513 & 513 & 516 & 516 & 517 & 522 & 526 & 529 & 529 & 531 & 532 & 533 & 563 & 564 & 572 & 687\end{array}$ 511

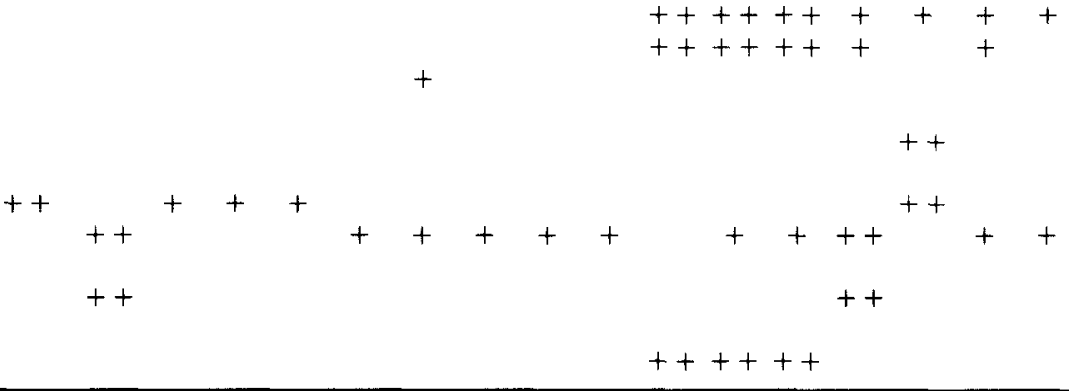

,+ Has the phenotype indicated in the first column; ++ , has stronger or the strongest effeet on the phenotype indicated. For details, see the text

addition, we describe another class of mutation: one which suppresses the nusA1 defect, permitting $\lambda$ growth at higher temperatures. We have assayed the effects of Rif $^{r}$ mutations on $\mathrm{N}$-mediated antitermination by determining the efficiency of $\lambda$ plating and by quantifying $\mathbf{N}$-dependent galK expression. These two assays showed excellent agreement. In addition, the use of both assays enabled us to determine that $\lambda$ plaque formation was inhibited when antitermination was reduced to about $10 \%$ of that normally observed for $r p o B^{+}$ parental strains at $32^{\circ} \mathrm{C}$ (Tables 3 and 4 ).

One Rif ${ }^{\mathrm{r}}$ mutant, rpoB3595, allowed $\lambda$ plating in the absence of $\mathbf{N}$ and is therefore an $\mathbf{N}$-bypass mutant. Interestingly, whereas expression from $\lambda \mathbf{P}_{\mathbf{R}}$ (assayed by $\lambda$ growth) was $\mathrm{N}$-independent, expression from $\lambda \mathrm{P}_{\mathrm{L}}$ (assayed by galK expression) was not. The Rif501 mutation, whose known mutational change is identical to that in rpoB3595 (Jin \& Gross, 1988) also shows $\mathrm{N}$-independent transcription from $\lambda \mathrm{P}_{\mathrm{R}}$ but not from $\lambda \mathrm{P}_{\mathrm{L}}$ (Lecocq \& Dambly, $1976 ;$ D. J. Jin, data not shown). The termination defect of rpoB3595 is probably responsible for the lack of $\mathrm{N}$-dependence of this Rif ${ }^{\mathrm{r}}$ mutant. Strains containing rpoB3595 (or rif501) were defective in termination at every Rho-dependent and Rhoindependent terminator we assayed (Jin et al., 1988). Very likely, the terminators in the $\lambda P_{\mathbf{L}}$ transcript are not ones that the rpoB3595 (rif501) mutant RNA polymerase can readthrough efficiently; hence antitermination is required for readthrough transcription from $\lambda P_{L}$.

Only one Rif ${ }^{r}$ mutant, rpoB111, exhibited a NusC phenotype, preventing $\lambda$ growth in an otherwise wild-type strain at $32^{\circ} \mathrm{C}$ but not at $42^{\circ} \mathrm{C}$. Although the plating phenotype is conditional, the defect in $\mathrm{N}$-mediated antitermination is actually manifest at both temperatures as measured by GalK assay. However, the fivefold decrease in $\mathrm{N}$ mediated antitermination at $12^{\circ} \mathrm{C}$ is not severe enough to prevent $\lambda$ growth at high temperature.
rpoB111 was also the only Rif $^{\mathrm{r}}$ mutation to fit the genetic criteria for an allele-specific suppressor of mutant nus $A$ alleles: it suppressed the termination defects of the nusA $10(\mathrm{Cs})$ allele but not those of the $n u s A 11(\mathrm{Ts})$ allele. The suppression assay for nus $A 10(\mathrm{Cs})$ was performed at $37^{\circ} \mathrm{C}$ while that for nusA11(Ts) was carried out at $30^{\circ} \mathrm{C}$. One could imagine that the lack of suppression of nus A11(Ts) resulted from a termination defect of rpoB111 at $30^{\circ} \mathrm{C}$. This is not the case. Strains containing rpoB111 show normal termination efficiency at these terminators in the presence of wild-type $n u s A^{+}$(D.J. Jin, unpublished data). If the rpoB111 allele defines a protein-protein contact between NusA and RNA polymerase, then an altered contact between the two proteins could be responsible for the NusC phenotype exhibited by this allele.

Five Rif ${ }^{\mathrm{r}}$ alleles (rpoB111, rpoB3445, rpoB8, rpoB113, and rpoB148) inhibit $\lambda$ plating on $n u s A I$ strains at low temperatures. The fact that rpoB111 affects antitermination on both $n u s A^{+}$and $n u s A 1$ strains while the effect of the other alleles is limited to $n u s A 1$ strains could simply reflect quantitative differences in the antitermination defect. The rpoB111 mutation restricted antitermination in the nusA1 strain much more severely than rpoB3445, the most restrictive of the four alleles affecting only nusA1 strains. On the other hand, there may be a qualitative difference between the mechanism of inhibition by rpoB111 and the other four alleles. The four alleles affecting antitermination only in nusA1 strains could be having an effect that is possible only in the presence of the defective nusA allele. The idea that these mutations may have a qualitatively different effect from rpoB111 is supported by their termination phenotypes. The four alleles whose effect is limited to the nusA $I$ strain map near each other (Jin \& Gross, 1988; see also Table 8) and increase termination at Rhodependent terminators (Jin et al., 1988). In 
contrast, the rpoB111 allele is actually defective in termination at Rho-independent terminators (Jin et $a l .$, 1988). Possibly, enhanced termination by the mutant RNA polymerases decreases antitermination in strains with the defective nusA1 allele without affecting antitermination in the wild-type strain. rpoB111, on the other hand, must affect antitermination in some other way, perhaps through altered interaction of RNA polymerase with NusA.

The class of RNA polymerase mutations partially suppressing the nusA1 restriction of $\mathrm{N}$-mediated antitermination at high temperatures has not been previously described. Two mutations, rpoB101 and rpoB3370, suppress nusA1 more than tenfold, while nine others suppress the defect several-fold. Of the 11 mutations suppressing the nusA1 defect, six had previously been shown to decrease termination, and three to increase termination, while two others had no effect upon termination (Jin et al., 1988). Thus, there does not seem to be a close correlation between these termination and antitermination phenotypes.

rpoB101 and rpoB3370, the two Rif ${ }^{\mathbf{r}}$ mutations that suppress the nusA1 phenotype most efficiently, are the only Rif $^{\top}$ mutations that suppress the termination defect of rhols (Das et al., 1978; Jin et al., 1988; Table 8). These two phenotypes may arise from the same defect in RNA polymerase. Either the alteration in RNA polymerase partially compensates for the defects in nusA1 and rho15 and bypasses the need for these proteins, or suppression results from altered interactions in the ternary complex. In vitro experiments indicate that RNA polymerase from rpoB101 does not simply bypass the need for Rho. The mutant RNA polymerase does not terminate by itself. Instead, it restores the ability of Rhols to hydrolyze ATP and terminate (Das et al., 1978) suggesting that suppression results from altered interactions in the ternary complex. Because NusA is known to bind to RNA polymerase and modify its termination properties, it is appealing to consider the possibility that suppression of rho15 might be mediated by altered interactions with NusA. Suppression of rho15 could result from altered contacts between NusA and RNA polymerase, or from indirect effects, possibly mediated by altered interactions of the ternary complex with the transcript.

\section{(c) Cellular antitermination phenotypes of Rif ${ }^{r}$ mutations}

This study has identified three Rif ${ }^{\mathbf{r}}$ mutations that cause a defect in cellular antitermination. These are the first RNA polymerase mutations affecting this process to be identified. These mutations alter amino acids 531 (rpoB114), 532 (rpoB3449) and 533 (rpoB3443) in the $\beta$ polypeptide. Our assay indicates that each of these mutations decreases the ability of the cellular antitermination system to readthrough the strong rrnT1 and $\mathrm{T}_{\mathrm{IS} 2}$ terminators carried in plasmid pES3
(Table 6). The fact that these mutations are highly clustered and have similar effects upon cellular antitermination suggests that this region of RNA polymerase plays a crucial role in cellular antitermination.

We do not think that the plasmid pES3 vector necessarily provides an accurate measure of the extent to which cellular antitermination is altered. First, the box $A$ site in the plasmid is mutant, which decreases the efficiency of the antitermination system significantly (M. Cashel, data not shown). Second, the cerminators in pES3 differ from those in the ribosomal RNA transcripts. The stable RNA transeript does not contain the IS 2 terminator and not all rrn operons contain the Tl terminator. The effects on antitermination we observed may well reflect the particular terminators chosen to assay this process. These differences may explain why mutations apparently inhibiting expression of stable RNA so severely are still viable.

The three Rif ${ }^{r}$ mutations that are defective in the cellular antitermination system involved in stable RNA synthesis could work either by decreasing antitermination or increasing termination. Our experiments suggest that the latter is the case. Although these Rif ${ }^{r}$ mutations do not affect termination at Rho-dependent or Rho-independent terminators (Jin et al., 1988), they were the only Rif $^{r}$ alleles that completely restored termination to strains containing the nusA10(Cs) or the nus $A 11$ (Ts) allele. It seems likely that the altered interaction of these Rif ${ }^{r}$ mutations at NusAdependent terminators such as $\operatorname{rrnA} \mathrm{Tl}$ uneovered in the mutant nus $A$ strains is responsible, at least in part, for their antitermination defect.

In summary, we have determined that alterations in the Rif $^{r}$ region of the $\beta$ subunit of RNA polymerasc have effects on both $\mathrm{N}$-mediated antitermination and the cellular antitermination system involved in expression of stable RNA. Many alterations in this region of the protein also alter the phenotypes of several nusA alleles, suggesting an interaction, either direct or indirect, between this region of $\beta$ and NusA. The effects of some of the Rif $^{r}$ mutations on antitermination may be explained by the termination capabilities of RNA polymerase containing the mutant $\beta$ subunit. Other effects on antitermination are not correlated with the termination phenotypes of the Rif $^{r}$ alleles. These effects may be explained by altered interactions with NusA protein or with some other component of the antitermination apparatus.

We thank M.Gottesman for suggesting that we perform $S_{1}$ mapping experiments to analyze the phenotypes of the Rif alleles affecting cellular antitermination, and for sending us strains. We thank K. McKenney for sending us plasmids. We also thank our colleagues, D. Cowing, J. Erickson and D. Straus, for helpful comments on the manuscript. This work was supported by a grant from the National Institutes of Health to C.A.G. 


\section{References}

Adams, C. W. \& Hatfield, G. W. (1984). J. Biol. Chem. 259, 7399-7403.

Adhya, S., Gottesman, M. \& de Crombrugghe, B. (1974). Proc. Nat. Acad. Sci., U.S.A. 71, 2534-2538.

Aksoy, S., Squires, C. L. \& Squires, C. (1984). J. Bacteriol. $159,260-264$.

Barik, S., Ghosh, B., Whalen, W., Lazinski, D. \& Das, A. (1987). Cell, 50, 885-899.

Baumann, M. F. \& Friedman, D. I. (1976). Virology, 73, $128-138$.

Berk, A. J. \& Sharp, P. A. (1978). Proc. Nat. Acad. Sci., U.S.A. 75, 1274-1278.

Brosius, J., Dull, T. J., Sleeter, D. D. \& Noller, H. F. (1981). J. Mol. Biol. 148, 107-127.

Chamberlin, M. J., Arndt, K. M., Briat, J.-F., Reynolds, R. L. \& Schmidt, M. C. (1987). In RNA Polymerase and the Regulation of Transcription, $A$ Steenbock Symposium (Reznikoff, W. S., Burgess, R. R., Dahlberg, J. E., Gross, C. A., Record, M. T., Jr \& Wickens, M. P. eds), pp. 347-356, Elsevier, New York.

Das, A. \& Wolska, K. (1984). Cell, 38, 165-173.

Das, A., Merril, C. \& Adhya, S. (1978). Proc. Nat. Acad. Sci, U.S.A. 75, 4828-4832.

de Crombrugghe, B., Mudryj, M., DiLauro, R. \& Gottesman, M. (1979). Cell, 18, 1145-1151.

Farnham, P. J., Greenblatt, J. \& Platt, T. (1982). Cell, 29, 945-951.

Fisher, R. \& Yanofsky, C. (1983). J. Biol. Chem. 258, 9208-9212.

Franklin, N. C. (1974). J. Mol. Biol. 89, 33-48.

Friedman, D. I. (1971). In The Bacteriophage Lambda (Hershey, A. D., ed.), pp. 733-738, Cold Spring Harbor Laboratory Press, Cold Spring Harbor, NY.

Friedman, D. 1. \& Baron, L. S. (1974). Virology, 58, 141148.

Friedman, D. I. \& Gottesman, M. (1983). In Lambda II (Hendrix, R. W. Roberts, J. W., Stahl, F. W. \& Weisberg, R. A. eds), pp. 21-51, Cold Spring Harbor Laboratory Press, Cold Spring Harbor, NY.

Friedman, D. I. \& Olson, E. R. (1983). Cell, 34, 143-149.

Friedman, D. I., Wilgus, G. S. \& Mural, R. J. (1973). J. Mol. Biol. 81, 505-516.

Friedman, D. I., Schauer, A. T., Baumann, M. R., Baron, L. S. \& Adhya, S. L. (1981). Proc. Nat. Acad. Sci., U.S.A. 78, 1115-1118.

Friedman, D. I., Olson, E. R., Georgopoulos, C., Tilly, K., Herskowitz, 'I. \& Banuett, F. (1984). Microbiol. Rev. 48, 229-325.

Georgopoulos, C. P. (1971). Proc. Nat. Acad. Sci., U.S.A. $68,2977-2981$.

Georgopoulos, C. P., Swindle, J., Keppel, F., Ballivet, M., Bisig, R. \& Eisen, H. (1980). Mol. Gen. Genet. 179, 55-61.

Ghysen, A. \& Pironio, M. (1972). J. Mol. Biol. 65, 259272.

Goda, Y. \& Greenblatt, J. (1985). Nucl. Acids Res. 13. 2569-2582.

Greenblatt, J. (1984). Can. J. Biochem. Cell Biol. 62, 7988.

Greenblatt, J. \& Li, J. (1981a). Cell, 24, 421-428.

Greenblatt, J. \& Li, J. (1981b). J. Mol. Biol. 147, 11-23.

Greenblatt, J., McLimont, M. \& Hanly, S. (1981). Nature (London), 292, 215-220.

Greenblatt, J., Horwitz, R. J. \& Li, J. (1986). In RNA Polymerase and the Regulation of Transcription. A Steenbock Symposium (Reznikoff, W. S., Burgess, R. R., Dahlberg, J. E., Gross, C. A., Record,
M. T., Jr \& Wickens, M. P. eds), pp. 357-366, Elsevier, New York.

Hammer, K., Jensen, K. F., Paulsen, P., Oppenheim, A. B. \& Gottesman, M. (1987). J. Bacteriol. 169, 5289-5297.

Holben, W. E. \& Morgan, E. A. (1984). Proc. Nat. Acad. Sci., U.S.A. 81, 6789-6793.

Horwitz, R. J., Li, J. \& Greenblatt, J. (1987). Cell, 51, 631-641.

Ishii, S., Hatada, E., Maekawa, T. \& Imamoto, F. (1984a). Nucl. Acids Res. 12, 4987-5003.

Ishii, S., Ihara, M., Maekawa, T., Nakamura, Y., Uchida, H. \& Imamoto, F. (1984b). Nucl. Acids Res. 12 , 3333-3342.

Jarvik, J. \& Botstein, D. (1975). Proc. Nat. Acad. Sci., U.S.A. 72, 2738-2742.

Jin, D. J. \& Gross, C. (1988). J. Mol. Biol. 202, 45-58.

Jin, D. J., Walter, W. \& Gross, C. (1988). J. Mol. Biol. 202, 245-253.

Kingston, R. \& Chamberlin, M. (1981). Cell, 27, 523-532.

Kung, H.-F., Spears, C. \& Weissbach, H. (1975). J. Biol. Chem. 250, 1556-1562.

Landick, R. \& Yanofsky, C. (1984). J. Biol. Chem. 259, 11550-11555.

Lau, L. F., Robert, J. W. \& Wu, R. (1983). J. Biol. Chem. 258, 9391-9397.

Lecocq, J. P. \& Dambly, C. (1976). Mol. Gen. Genet. 145, 53-64.

Li, S. C., Squires, C. L. \& Squires, C. (1984). Cell, 38, 851860.

Mandel, M. \& Higa, A. (1970). J. Mol. Biol. 53, 159-162.

Maniatis, T., Fritsch, E. F. \& Sambrook, J. (1982). Molecular Cloning: A Laboratory Manual, Cold Spring Harbor Laboratory Press, Cold Spring Harbor, NY.

Maxam, A. \& Gilbert, W. (1980). In Methods in Enzymology (Grossman, L. \& Moldave, K., eds), vol. 65, pp. 499-560, Academic Press, New York.

McKenney, K., Shimatake, H., Court, D., Schmeissner, U., Brady, C. \& Rosenberg, M. (1981). In Gene Amplication and Analysis, II: Analysis of Nucleic Acids by Enzymatic Methods (Chirikjian, J. G. \& Papas, T. S., eds), pp. 383-415, Elsevier-North Holland, New York.

Miller, J. H. (1972). Experiments in Molecular Genetics, Cold Spring Harbor Laboratory Press, Cold Spring Harbor, NY

Morgan, E. (1986). J. Bacteriol. 168, 1-5.

Morrison, D. A. (1979). In Methods in Enzymology (Wu, R., ed), vol. 68, pp. 326-331, Academic Press, New York.

Nakamura, Y., Mizusawa, S., Court,D. L. \& Tsugawa, A. (1986a). J. Mol. Biol. 189, 103-112.

Nakamura, Y., Mizusawa, S., Tsugawa, A.\& Imai, A. (1986b). Mol. Gen. Genet. 204, 24-28.

Olson, E. R., Tomich, C.-S. C. \& Friedman, D. I. (1984). J. Mol. Biol. 180, 1053-1064.

Peltz, S. W., Brown, A. L., Hasan, N., Podhajska, A. J. \& Szybalski, W. (1985). Science, 228, 91-93.

Rosenberg, M., Court, D., Shimatake, H., Brady, C. \& Wulff, D. L. (1978). Nature (London), 272, 414-423.

Salser, W., Gesteland, R. F. \& Bolle, A. (1967). Nature (London), 215, 588 591 .

Salstrom, J. S. \& Szybalski, W. (1978). J. Mol. Biol. 124 , 195-221.

Sarmientos, P., Sylvester, J. E., Contente, S. \& Cashel, M. (1983). Cell, 32, 1337-1346

Schauer, A. T., Carver, D. L., Bigelow, B., Baron, L. S. \& Friedman, D. I. (1987). J. Mol. Biol. 194, 679-690

Schmidt, M. C. \& Chamberlin, M. J. (1984). Biochemistry, 23. 197-203. 
Schmidt, M. C. \& Chamberlin, M. J. (1987). J. Mol. Biol. $195,809-818$.

Sharrock, R. A., Gourse, R. L. \& Nomura, M. (1985). Proc. Nat. Acad. Sci., U.S.A. 82, 5275-5279.

Simon, L. D., Gottesman, M., Tomczak, K. \& Gottesman, S. (1979). Proc. Nat. Acad. Sci., U.S.A. 76, 16231627.

Sternberg, N. (1973). J. Mol. Biol. 76, 25-44.

Sternberg, N. (1976). Virology, 73, 139-154.

Strauch, M. \& Friedman, D. I. (1981). Mol. Gen. Genet. $182,498-501$.
Swindle, J., Ajioka, J. \& Georgopoulos, C. (1981). Mol. Gen. Genet. 182, 409-413.

Tomizawa, J.-I. (1985). Cell, 40, 527-535.

Ward, D. F. \& Gottesman, M. E. (1981). Nature (London), 292, 212-215.

Ward, D. R., DeLong, A. \& Gottesman, M. E. (1983). J. Mol. Biol. 168, 73-85.

Warren, F. \& Das, A. (1984). Proc. Nat. Acad. Sci., U.S.A. 81, 3612-3616.

Edited by M. Gottesman 